\title{
Improvement of hydrogen production of Chlamydomonas reinhardtii by co-cultivation with isolated bacteria
}

\author{
Xiaoxu Li ${ }^{a, b}$, Shi Huang ${ }^{c}$, Jun $\mathrm{Yu}^{b}$, Quanxi Wang ${ }^{a, * *}$, Shuangxiu $\mathrm{Wu}^{b, *}$ \\ ${ }^{a}$ College of Life and Environmental Science, Shanghai Normal University, No. 100 Guilin Road, Xuhui District, \\ Shanghai 200234, PR China \\ ${ }^{\mathrm{b}}$ Beijing Institute of Genomics, Chinese Academy of Sciences, No.1-7 Beichen West Road, Chaoyang District, Beijing \\ 100101, PR China \\ ${ }^{c}$ Qingdao Institute of BioEnergy and Bioprocess Technology, Chinese Academy of Sciences, No. 189 Songling Road, \\ Laoshan District, Qingdao, PR China
}

\section{A R T I C L E I N F O}

\section{Article history:}

Received 29 November 2012

Received in revised form

15 February 2013

Accepted 22 February 2013

Available online 2 April 2013

\section{Keywords:}

Chlamydomonas reinhardtii

Co-culture

Isolated bacteria

Hydrogen production

\begin{abstract}
A B S T R A C T
Three bacteria, named L2, L3 and L4, were isolated from contaminated cultures of Chlamydomonas reinhardtii strain cc849 in laboratory. The phylogenetic analysis based on $16 \mathrm{~S}$ rDNA sequences showed that L2, L3 and L4 belonged to genus Stenotrophomonas, Microbacterium and Pseudomonas, respectively. The co-cultivation of isolated L2, L3 and L4 with purified algae, respectively, demonstrated that moderate bacterial concentration did not affect algal growth significantly but improved algal $\mathrm{H}_{2}$ production obviously. The maximal $\mathrm{H}_{2}$ yields were gained by the co-culture of algae with $\mathrm{L} 2$ or L4, about 4.0 times higher than that of the single algal culture. Increased respiration rate or $\mathrm{O}_{2}$ consumption was the main reason for the enhancement of $\mathrm{H}_{2}$ yield of the co-cultures.
\end{abstract}

Copyright @ 2013, Hydrogen Energy Publications, LLC. Published by Elsevier Ltd. All rights

reserved.

\section{Introduction}

Photobiological production of $\mathrm{H}_{2}$ by green algae has great potential to be used for generating renewable and clean fuel from nature's most plentiful resources, i.e. light and water, to replace the traditional fossil fuels in the future [1,13]. At present, a green alga, Chlamydomonas reinhardtii has been chosen to be a model species for studying photohydrogen production because its Fe-hydrogenase, the key enzyme for $\mathrm{H}_{2}$ production, has high activity, its culture is easy, and its genomic background is comprehensible (reviewed by Ref. [14]).
However, Fe-hydrogenase is highly oxygen sensitive [2], while $\mathrm{O}_{2}$ is the principal product of algal photosynthesis, leading to low efficiency of $\mathrm{H}_{2}$ production and inhibiting industrial utilization of this technology. Many efforts, relying on physiochemical and molecular biology methods, have been attempted to enhance $\mathrm{H}_{2}$ productivity in algae. The landmark method is to use a sulfur-deprived medium for the inactivation of $\mathrm{O}_{2}$ evolution at algal PSII (Photosystem II) under illumination, to create an anaerobic condition and enactive Fehydrogenase [13], thus finally to significantly prolong $\mathrm{H}_{2}$ production time for better $\mathrm{H}_{2}$ yield.

\footnotetext{
* Corresponding author. Tel.: +86 10 82995394; fax: +86 1082995382.

** Corresponding author. Department of Biology, College of Life and Environmental Science, Shanghai Normal University, No. 100 Guilin Road, Xuhui District, Shanghai 200234, PR China. Tel./fax: +86 2162342141.

E-mail addresses: wangqx@shnu.edu.cn (Q. Wang), wushx@big.ac.cn, bowusx@shnu.edu.cn (S. Wu). 0360-3199/\$ - see front matter Copyright @ 2013, Hydrogen Energy Publications, LLC. Published by Elsevier Ltd. All rights reserved. http://dx.doi.org/10.1016/j.ijhydene.2013.02.102
} 
Aside from the above method, strategies of co-cultivation of algae and bacteria were also attempted. For instance, Kawaguchi et al. [8] grew photosynthetic bacterium Rhodobium marinum and Lactobacillus amylovorus along with algal biomass for metabolizing the algal starch into lactate as an electron donor for hydrogen production in bacteria. Melis et al. [12] co-cultivated photosynthetic, hydrogen-producing algae (wild type and genetically engineered for reduced sulfate utilization) with a hydrogen-producing bacterium, Rhodospirillium rubrum for a successful enhancement of $\mathrm{H}_{2}$ production. Kim et al. [9] described that incubation of algal biomass of $C$. reinhardtii with Clostridium butyricum and Rhodobacter sphaeroides KD131 under anaerobic and photosynthetic fermentation conditions to improve $\mathrm{H}_{2}$ production. Similar results have also been reported by Refs. $[15,16]$.

Actually, microalgae in large-scale cultivation are always associated with growing of other microbes, and these microbes often conversely affect algal growth and metabolism. Watanabe et al. [23] had isolated four bacterial strains and one fungal strain from a green alga Chlorella sorokiniana culture and proved that bacterium Microbacterium trichotecenolyticum and funga Acremonium-like hyphomycete could promote Chlorella growth. Rivas et al. [20] had isolated and identified two species, Pseudomonas sp. and Rhizobium sp. from microalgal Botryococcus braunii cultures, and found Rhizobium sp. increased the algal growth significantly. Park et al. [18] also reported that the isolated bacteria, highly homologous with Breuundimonas nasdae and Breuundimonas vesicularis, improved algal growth in a longterm laboratory culture of the green alga Chlorella ellipsoidea. These cases show that the interaction between algae and its symbionts involved both mutualism and commensalism.

In our laboratory, repeated routine cultures of $C$. reinhardtii strain cc849 (Cr849) were easily contaminated by bacteria. After contamination, the liquid media of algal cultures became slightly milky, and some colonies with white or yellowish color and round shape formed on agar plates during algal subcultures, showing it might be bacterial contamination. We also found these bacteria could coexist with the algae on agar plates for a long term. However, what these bacteria are and whether they affect the growth and $\mathrm{H}_{2}$ production of $C$. reinhardtii are not clear. In this study, we isolated and purified three bacteria from the contaminated cultures of $\mathrm{Cr} 849$ on different media, identified them based on phylogenetic analyses of 16S rDNA sequences, and also investigated their effects on algal growth and $\mathrm{H}_{2}$ production. The results will direct algal culture strategy for further improvement of $\mathrm{H}_{2}$ productivity of $\mathrm{C}$. reinhardtii.

\section{Material and methods}

\subsection{Algal materials and cultures}

The regular culturing and purification of $\mathrm{Cr} 849$ were carried out as our previous reports $[6,24]$ or in the Supplemental Material S.1 and S.2.

\subsection{Isolation of bacteria from contaminated algal cultures}

$1 \mathrm{ml}$ of contaminated algal cultures at different growth periods were taken and diluted by $10^{-1}, 10^{-2}$ and $10^{-3}$ times with the sterile Tris-acetate-phosphate (TAP, $\mathrm{pH}$ 7.0) medium before streaked on TAP agar plates, TAP-LB agar plates (mixed by TAP medium and LB medium [21] with the volume ratio at 1:1) and YEM agar plates [19], respectively. The cultures were incubated at $25^{\circ} \mathrm{C}, 28-30^{\circ} \mathrm{C}$ and $37^{\circ} \mathrm{C}$, respectively, until bacterial colonies grew up. The colonies were picked up one by one and subcultured on the solid media, on which they originally grew up, for many times to get pure colonies.

\subsection{Preparation of bacterial genome DNA}

A $2 \mathrm{ml}$ of each isolated bacterial colony cultures in the exponential growth phase were taken for DNA extraction by the routine $\mathrm{NaCl}-$ CTAB method [21], as mentioned in Supplemental Material S.3.

\subsection{Phylogenetic analysis based on 16S rDNA sequences}

Bacterial 16S rDNA fragments were amplified as reported by Park et al. [18] or as in the Supplemental Material S.4, sequenced in Beijing Genomics Institute, Shenzhen, China. The sequences were analyzed by using BioEdit and Blast programs in GenBank (www.ncbi.nlm.nih.gov/blast/Blast.cgi) and aligned by using ClustalX V2.0 software. The phylogenetic trees were calculated by using the maximum likelihood algorithm with full-length 16S rDNA sequences of nearest neighbours for determination of their phylogenetic position.

\subsection{Co-cultures of algae and isolated bacteria and their growth, $\mathrm{O}_{2}, \mathrm{H}_{2}$ measurements}

Both purified algal and bacterial cultures were collected at the late exponential phase, washed for three times, resuspended in fresh TAP medium with cell densities at $1 \times 10^{7}{\text { cells } \mathrm{ml}^{-1}}^{-1}$ (for algae) and $\mathrm{OD}_{600}$ of 1.0 (for bacteria), mixed together at variant ratios, respectively, and grew at $25^{\circ} \mathrm{C}$ in $60 \mu \mathrm{mol}$ $\mathrm{m}^{-2} \mathrm{~s}^{-1}$ of light intensity, the optimized conditions for algal growth and hydrogen production proved in our previous work [26], to observe their growth, $\mathrm{O}_{2}$ evolution and $\mathrm{O}_{2}$ consumption or $\mathrm{H}_{2}$ and $\mathrm{O}_{2}$ contents in the headspace of the cultures for 1-2 weeks [11,24]. Purified cultures of Cr849, L2, L3, and L4 were set as the control. The detail procedures were in Supplemental Material S.5 and S.6.

\section{Results}

\subsection{Isolation and identification of alga-associated bacteria}

C. reinhardtii is frequently contaminated by bacteria in laboratory routine cultures, but sometimes the algal growth on TAP plates seems not to be affected by bacteria. In this work, we used three different agar media to isolate bacteria from the contaminated algal cultures of Cr849. After five rounds of isolation and purification, two single colonies, named L2 and L3, which were transparent, small-size colony and milky yellow color, big-size colony, respectively, were isolated from the TAP-LB plate. One single colony, named L4, with small-size and transparent color, was isolated from the YEM plate. 
Three above isolated bacterial colonies were identified by sequencing of their $16 \mathrm{~S}$ rDNA genes and phylogenetic analysis respectively. The results showed that $16 \mathrm{~S}$ rDNA sequences of L2, L3 and L4 had high similarity, up to $99 \%, 100 \%$ and $99 \%$, with that of Stenotrophomonas maltophilia strain 776, Microbacterium paraoxydans strain 591 and Pseudomonas sp. A8, respectively, based on the GenBank data (Fig. 1). The $16 \mathrm{~S}$ rDNA gene sequences of L2, L3 and L4 were submitted to the Genbank with the accession number of JQ946047, JQ946048, and JQ946049, respectively.

3.2. The growth of co-culture of algae and isolated bacteria

To study the effect of isolated bacteria on the growth of $\mathrm{Cr} 849$, each isolated bacterial solution, with the cell concentration at $\mathrm{OD}_{600}$ of 1.0, was added into the purified algal culture with the volume ratio (bacteria to algae) of $2 \mathrm{ml}: 30 \mathrm{ml}$. The growth of co-cultures was detected every day for 7 days. Pure cultures of Cr849, and bacteria L2, L3 and L4 were set as the control, respectively (Fig. 2A). The results showed that the growth periods of both bacteria and algae were not affected significantly after co-cultivation, compared with those of control cultures (Fig. 2A, B). For bacteria, they all grew to saturation levels within 2 days and kept in constant in the following days both in their pure-culture and co-culture conditions (Fig. 2A). Moreover, the growths of all three bacteria were improved obviously by co-cultivation with algae (Fig. 2A). For algae, the maximal algal cell density of all the cultures appeared on Day 4 (Fig. 2B). Furthermore, L2 and L3 did not inhibited algal growth significantly, and their maximal algal cell density were about $3.67 \times 10^{7} \mathrm{ml}^{-1}$ and $3.48 \times 10^{7} \mathrm{ml}^{-1}$, respectively, similar to that of purified algal culture, about $3.56 \times 10^{7} \mathrm{ml}^{-1}$. On the contrary, the maximal algal cell density of the co-culture with L4 was only about $2.90 \times 10^{7} \mathrm{ml}^{-1}$, with about $18.5 \%$ decreased. Therefore, in moderate inoculation concentration, bacterium L2 and L3 did not affect the algal growth significantly but bacterium L4 inhibited the algal growth slightly.

\subsection{Effect of isolated bacteria on hydrogen production of Cr849}

To test whether isolated bacteria L2, L3 and L4 affected $\mathrm{H}_{2}$ production of $\mathrm{Cr} 849$, each isolated bacterial solution was mixed with purified algal culture in different inoculation ratios and cultured under hydrogen production condition. The results showed that all three isolate bacteria promoted algal $\mathrm{H}_{2}$ accumulation significantly (Fig. 3). Furthermore, the promotion effect was concerned with the inoculation ratio of algae to bacteria. The maximal $\mathrm{H}_{2}$ yield, about $60.16 \mu \mathrm{mol}$, $43.83 \mu \mathrm{mol}$ and $62.66 \mu \mathrm{mol}$, was gained when the algal culture was mixed with the bacterial solution L2, L3 and L4 in the volume ratio at 8:1, 200:1 and 8:1, respectively, about 4.0, 2.9 and 4.1 times higher than that of pure algal culture, nearly $15.11 \mu \mathrm{mol}$. To increase or decrease the bacterial inoculation quantity consequently led to a decrease in the algal $\mathrm{H}_{2}$ accumulation of the co-cultures (Fig. 3).

At the optimal inoculation ratio of algae to isolated bacteria for the maximal $\mathrm{H}_{2}$ production, the dynamics of $\mathrm{H}_{2}$ and $\mathrm{O}_{2}$ accumulation in the headspace of the cultures were monitored (Fig. 4A, B). The results showed that $\mathrm{H}_{2}$ accumulation of the co-cultures lagged in the first 5 days but increased rapidly

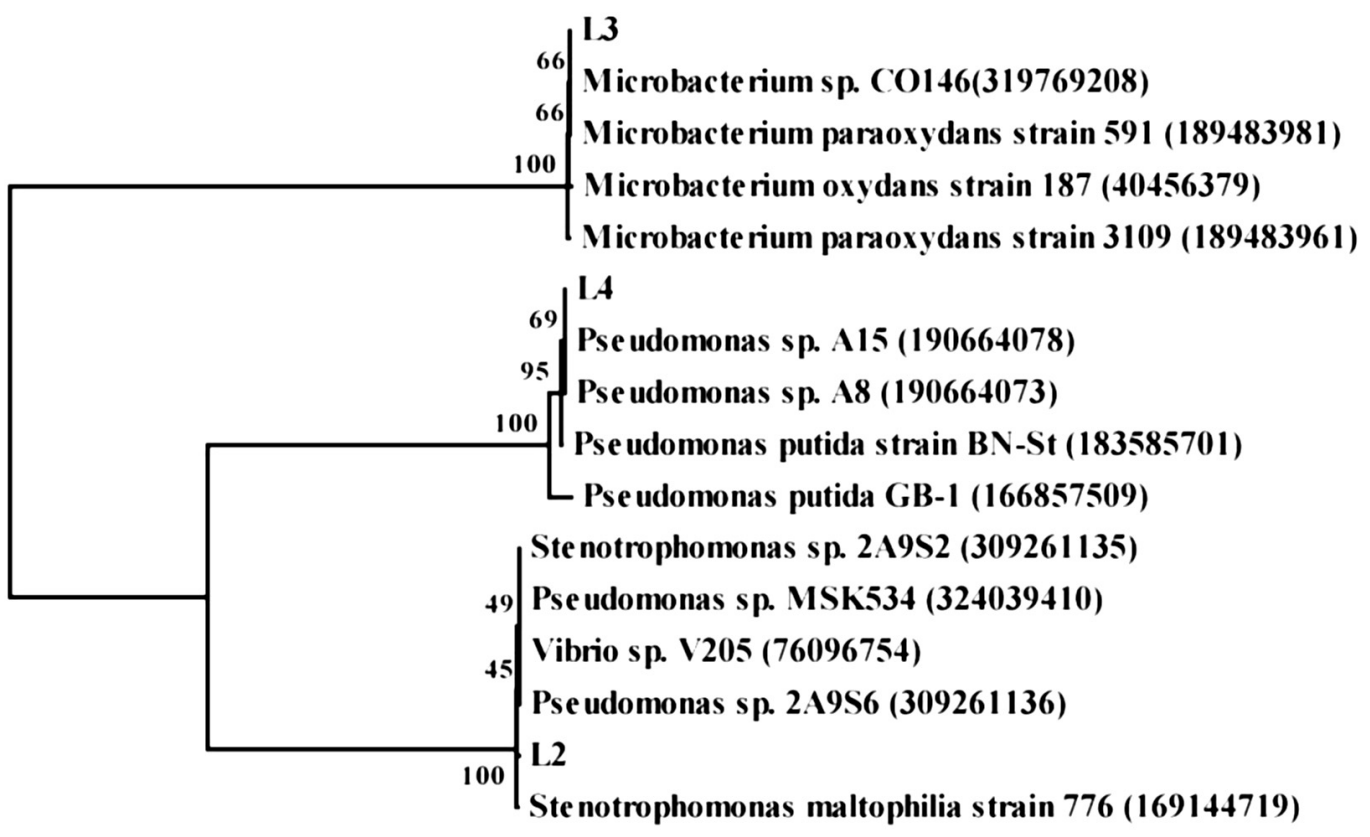

$$
\underset{0.01}{\longmapsto}
$$

Fig. 1 - Phylogenetic analysis of bacteria isolated from contaminated cultures of C. reinhardtii strain cc849 based on 16S rDNA sequences. Phylogenetic trees were constructed by the bootstrapping and maximum-likelihood rule. Numbers at each branch points indicate bootstrap confidence values as the percentage of 1000 bootstrap replications. Numbers in parentheses represent the sequences' accession number in GenBank. Bar indicates 0.01 substitutions per nucleotide. 

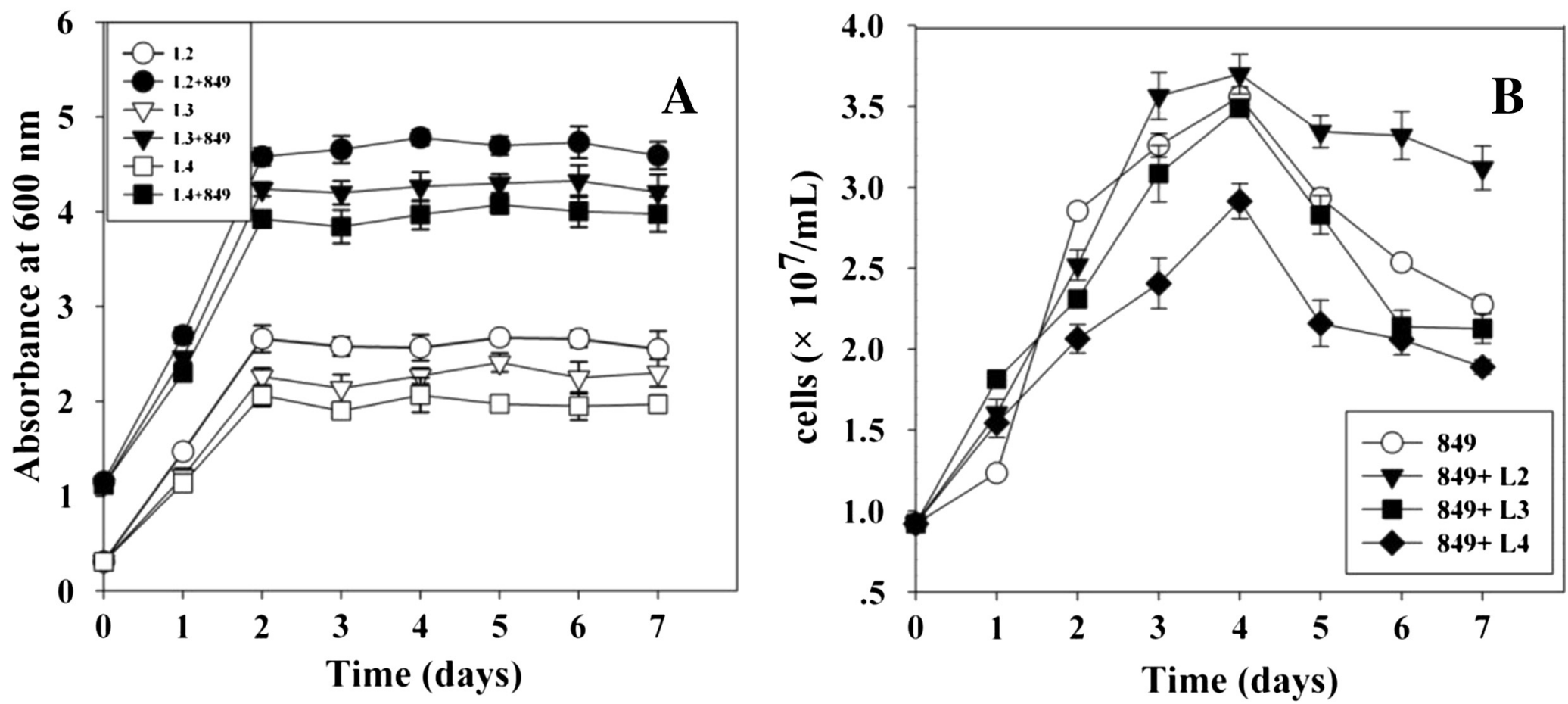

Fig. 2 - Growth of bacteria L2, L3 and L4 (A) as well as the co-cultures of Cr849 and isolated bacteria L2, L3 and L4 (B). The growth of bacteria was indicated by their absorbance at $600 \mathrm{~nm}$ (A). The growth of Cr849 was shown by cell numbers accounted under the microscopy (B). 


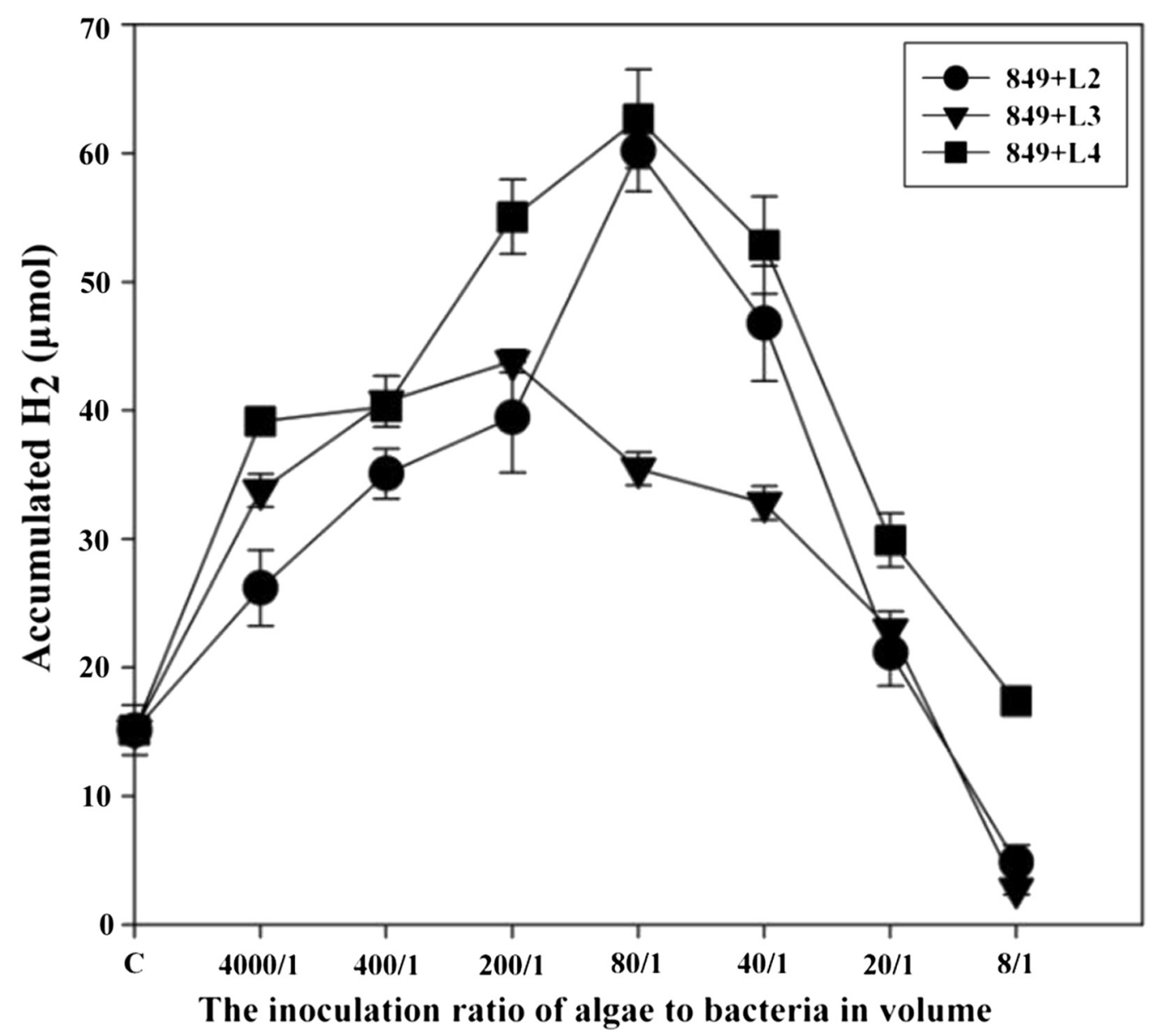

Fig. 3 - The effects of different bacterial cell density on the hydrogen production of C. reinhardtii strain cc849. "C" in X-axile refers to "control".

and significantly from Day 6 and reached the maximal levels at Days 9-10 (Fig. 4A). Especially for the algal co-culture with $\mathrm{L} 2$ and L4, the maximal $\mathrm{H}_{2}$ accumulation reached 60.1-61.5 $\mu \mathrm{mol}$, which was 4.0-4.1 times higher than that of the single $\mathrm{Cr} 849$ culture. While the maximal $\mathrm{H}_{2}$ production of the algal co-culture with L3 was around $44.0 \mu \mathrm{mol}$, about 2.9 times higher than that of the single $\mathrm{Cr} 849$ culture.

On the contrary, the $\mathrm{O}_{2}$ content in the headspace of each co-culture decreased more quickly than that of the pure algal and bacterial cultures (Fig. 4B) and reached minimal level at $5.7-6.4 \%$ on Day 2 and kept in such low levels in the following days. Whereas $\mathrm{O}_{2}$ content in the headspace of the single algal and bacterial culture decreased gradually to $7.6 \%$ and $6.6 \%$, respectively, until Day 6 and kept in such high level in the following days.

\subsection{Oxygen evolution and consumption in the co- cultures of algae and bacteria}

Using a Clark-type electrode, the changes of dissolved oxygen contents (DOC) in the co-cultures of $\mathrm{Cr} 849$ and isolated bacteria L2, L3 and L4 were measured respectively in both normal TAP and TAP-S medium. We found, in TAP medium, there was no net photosynthetic oxygen evolution detected, even under high light intensity (data not shown). However, the respiration rates of the co-culture systems were obviously enhanced compared with that of the pure algal culture (Fig. 5). During 7-day's period, the respiration rate of the pure algae kept constant at 4.46-4.49 $\mathrm{mol} \mathrm{O}_{2} \mathrm{mg}^{-1} \mathrm{chl} \mathrm{h}^{-1}$, while those of the co-cultures were all increased gradually since the first day of cocultivation and arrived the saturation level on Day 6, about $5.61 \mu \mathrm{mol} \mathrm{O}_{2} \mathrm{mg}^{-1} \mathrm{chl} \mathrm{h}^{-1}, 5.51 \mu \mathrm{mol} \mathrm{O}_{2} \mathrm{mg}^{-1} \mathrm{chl} \mathrm{h}^{-1}$ and 5.31 $\mu \mathrm{mol} \mathrm{O}_{2} \mathrm{mg}^{-1} \mathrm{chl} \mathrm{h}^{-1}$ for the algal co-cultures with L4, L2 and L3, respectively, for about $25 \%, 23 \%$ and $18 \%$ higher than that of the pure algal culture, respectively.

In TAP-S medium for $\mathrm{H}_{2}$ production, photosynthetic oxygen evolution of the co-cultures was inhibited due to sulfur deprivation and not detectable neither (data not shown). In the first 3 days of the cultivation, the respiration rate of the pure algal culture kept at about $4.68-6.59 \mu \mathrm{mol} \mathrm{O}_{2} \mathrm{mg}^{-1} \mathrm{chl} \mathrm{h}^{-1}$ (Fig. 6), whereas those of the co-cultures with isolated bacteria were extremely stimulated in the first two days but could not be detected since the 3rd day. Particularly for the algal cocultures with $\mathrm{L} 2$ and $\mathrm{L} 4$, the highest respiration rate on the 1st day was about $34.796-36.273 \mu \mathrm{mol} \mathrm{O}_{2} \mathrm{mg}^{-1} \mathrm{chl} \mathrm{h}^{-1}$, which was 7-8 times higher than that of purified algae, but decreased by almost $45 \%$ on the 2 nd day. The respiration rate of the algal co-culture with L3 was slightly less than other two bacteria's 

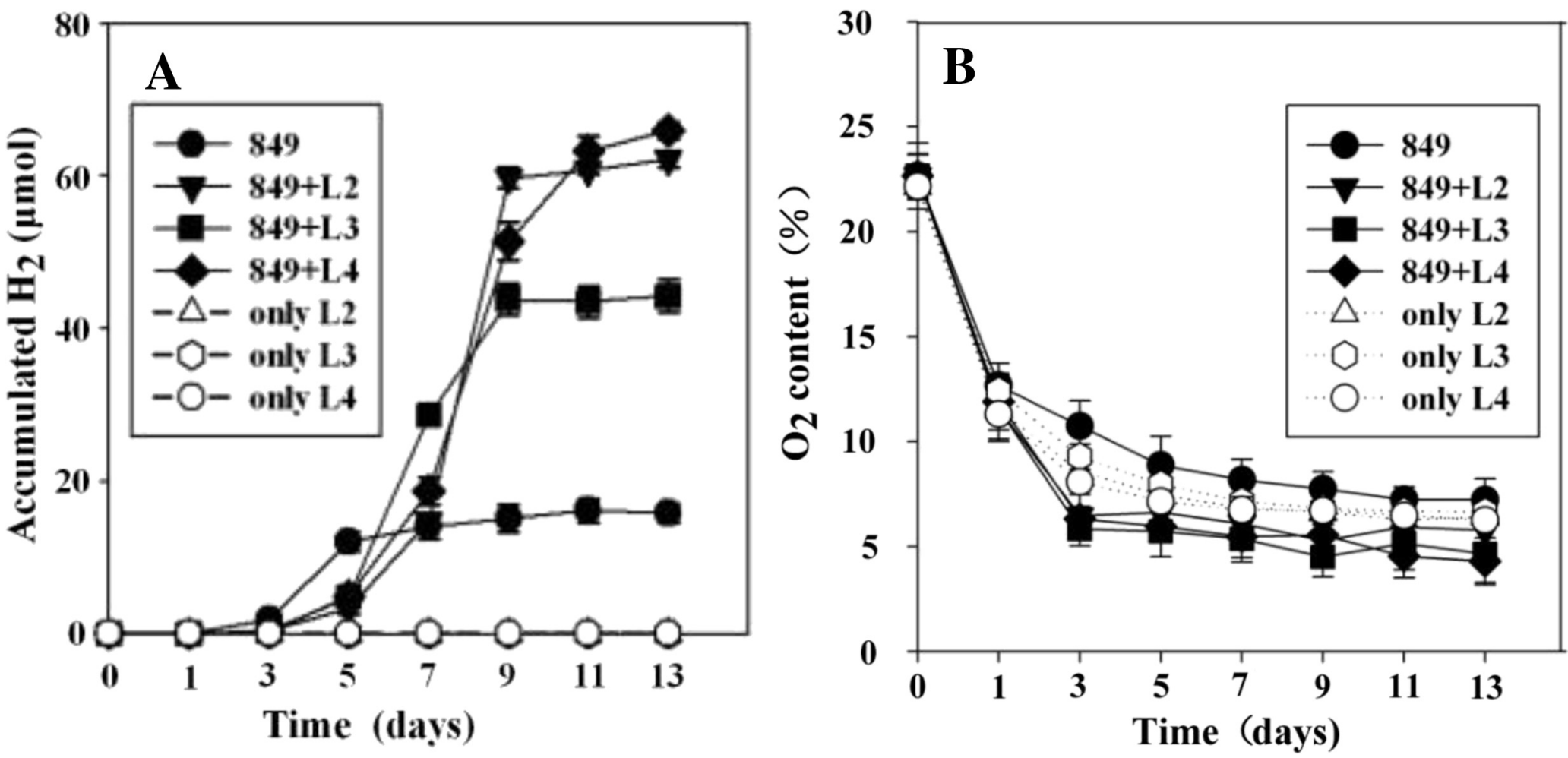

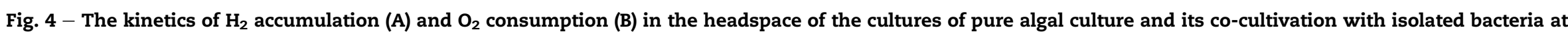
optimal inoculation ratios. 


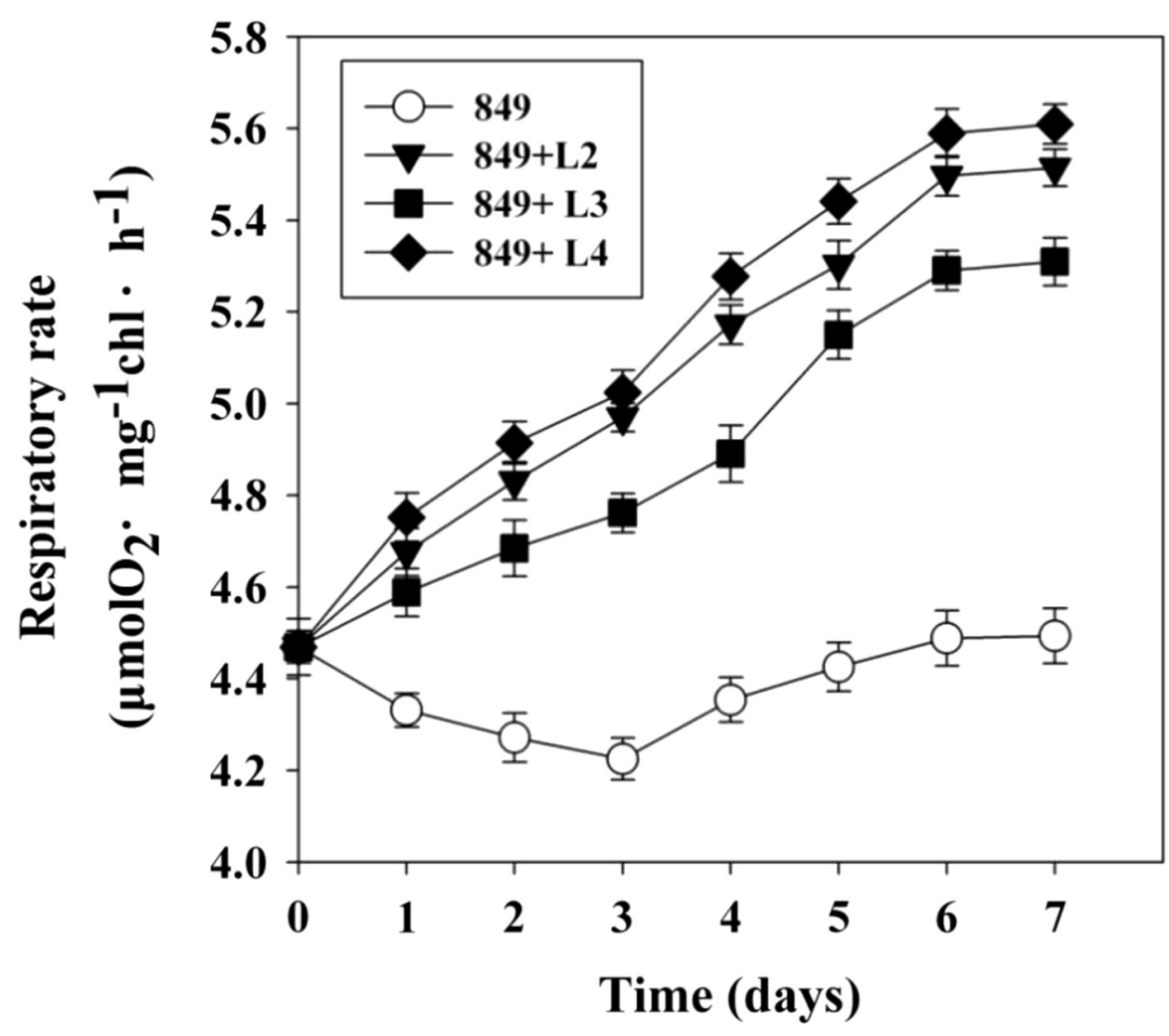

Fig. 5 - The respiration rate of Cr849 and its co-cultures with isolated bacteria in TAP medium.

co-cultures, around $26.796 \mu \mathrm{mol} \mathrm{O}_{2} \mathrm{mg}^{-1} \mathrm{chl} \mathrm{h}^{-1}$ on 1st day and decreased by $50 \%$ on the 2 nd day in TAP-S medium.

\section{Discussion}

Cr849 is used to study the mechanism of green algal photohydrogen production in our laboratory though its hydrogen productivity is lower than the common used strain cc124 [25] because it is a cell wall-deficient mutant and easy for molecular manipulations. The algae are frequently contaminated during routine culture work, especially in large-scale cultures. Faintly milky bacterial colonies formed along the algal colonies and coexisted with the algae on agar plates for a long term. In this work, we isolated three bacteria, named L2, L3 and L4, from contaminated cultures of Cr849 and identified by the phylogenetic analysis based on their 16S rDNA sequences. L2, L3 and L4 showed high similarity, up to $99 \%, 100 \%$ and $99 \%$, to S. maltophilia strain 776, M. paraoxydans strain 591 and Pseudomonas sp. A8, respectively (Fig. 1). S. maltophilia is an aerobic, nonfermentative, gram-negative bacterium and ubiquitous in aqueous environments, soils, plants and foods (frozen fish, milk, eggs, etc.) [3]. M. paraoxydans is a strictly aerobic, grampositive, coryneform bacterium [10]. Pseudomonas species are strictly aerobic, gram-negative, rod-shaped bacteria that are found in most saprotrophic soil and water habitats and have a very diverse metabolism, including the ability to degrade organic solvents which are significant to the environment and used in bioremediation to control pollution [17]. All these bacteria are aerobic, grow well around $25-30^{\circ} \mathrm{C}$ and in low nutrition supplies by using a variety of carbon and nitrogen sources for growth, which $C$. reinhardtii could supply for.

Pseudomonas, Bacillus, Microbacterium and Agrobacterium are usually plants endosymbionts in nature [4], which refer to that microorganisms in certain stage of life history live in living plant tissues, without causing significant plant disease [7], widely distributed in lower plants and higher plants [4]. In this work, purified bacterium L2 of Stenotrophomonas genus, bacterium L3 of Microbacterium genus and bacterium L4 of Pseudomonas genus could long-term habitat with Cr849 on the TAP agar plate at room temperature in laboratory conditions, seemed no toxic to the algae. However, their relationship and interaction mechanism with C. reinhardtii need further study. Especially for bacterium L4, it shows high similarity to Pseudomonas sp. A8, which was reported to be also found in the cyanobacterial cultures [22].

Furthermore, these bacteria considerably enhanced $\mathrm{H}_{2}$ accumulation of $\mathrm{Cr} 849$ (Figs. 3 and 4). The maximal $\mathrm{H}_{2}$ yield of the co-cultures of the isolated bacteria and algae was about 4 times higher than that of the pure algal cultures of Cr849, equal to the common $\mathrm{H}_{2}$ yield of green algae [25]. These bacteria could be thought to be stronger than the one produced by genetic techniques because they are isolated from natural algae cultures. Therefore, these bacteria have potential to be used to improve the $\mathrm{H}_{2}$ production of $\mathrm{C}$. reinhardtii by introducing them with proper concentrations into the algal 


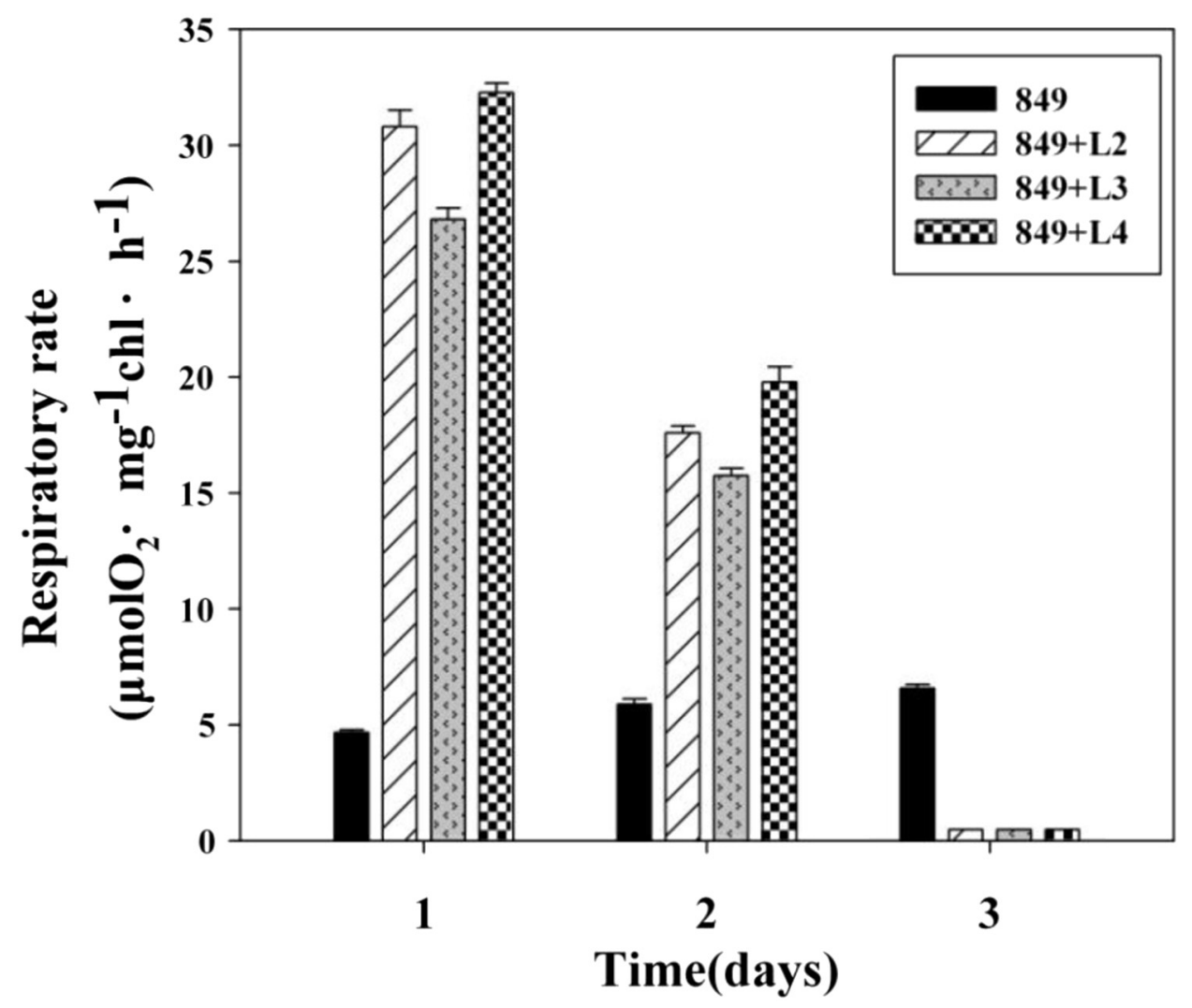

Fig. 6 - The respiration rate of C. reinhardtii strain cc849 and its co-cultures with isolated bacteria in TAP-S medium and anaerobic conditions for hydrogen production.

cultures in hydrogen production conditions. Furthermore, these bacteria are aerobic and cannot survive for long time in the anaerobic hydrogen production condition, indicating the utilization of these bacteria for this purpose is easily under control when considering the problems of environmental protection.

The main reason for the improvement of $\mathrm{H}_{2}$ accumulation of the co-cultures of isolated bacteria and algae was demonstrated to be the increase of the respiration rate of the cocultures both under normal conditions (Fig. 5) and under anoxia conditions (Fig. 6). Especially under anoxia condition for $\mathrm{H}_{2}$ production, the respiration rates of co-cultures of bacteria L2 and L4 with algae were 7-8 times higher than that of the purified algal culture (Fig. 6). High respiration rates in the co-cultures of bacteria and algae led to rapid $\mathrm{O}_{2}$ consumption in the cultures, resulting in the improvement of activity of hydrogenase, the anaerobic-induced enzyme, and thus leading to enhancement of $\mathrm{H}_{2}$ yield. The results were in accord with the aerobic characteristics of these bacteria. However, high concentrations of isolated bacteria inhibited the $\mathrm{H}_{2}$ yield of the co-cultures (Fig. 3). One reason may be that a large quantity of bacterial fermentation metabolites under anaerobic condition inhibited the $\mathrm{H}_{2}$ metabolism of $C$. reinhardtii. Another reason might be that high concentrations of bacteria competed carbohydrate materials, which provide protons and electrons through glycolysis pathway, with $\mathrm{H}_{2}$ metabolism of C. reinhardtii [5].
Most interestingly, the net photosynthetic oxygen evolution of the co-cultures of isolated bacteria and purified algae was not detectable even under normal culture condition and in normal TAP medium (data not shown). The main reason might be the increase of the respiration rate of the co-cultures, even though it was only $18-25 \%$ increased compared with that of pure algal cultures. However, because the DOC which can be used for the respiration metabolism in liquid medium is much lower than that in the air, even small decrease or increase of DOC in the medium would cause significant effects on algal essential metabolisms, including respiration and photosynthetic metabolisms. Further examination on algal cell growth showed that algal cells begun to break after one week of the co-cultivation, indicating that such low oxygen condition or fermentation metabolism in such condition, possibly also including bacterial toxicity, seriously inhibited algal normal growing process in the co-cultures. The detail reason should be revealed by using further physiological, biochemistry and molecular techniques, which were undergoing in our laboratory.

\section{Acknowledgment}

This work was supported by grants from NSFC31271397, the SOA Key Laboratory for Polar Science, Polar Research Institute of China (KP201107). We also thank the support from the CAS Key Laboratory of Genome Sciences and Information, Beijing 
Institute of Genomics, Chinese Academy of Sciences and the Leading Academic Discipline Project of Shanghai Municipal Education Commission (No. J50401). The authors have no conflict of interest to declare.

\section{Appendix A. Supplementary data}

Supplementary data related to this article can be found in the online version at doi:10.1016/j.ijhydene.2013.02.102.

\section{R E F E R E N C E S}

[1] Esper B, Badura A, Rögner M. Photosynthesis as a power supply for (bio-)hydrogen production. Trends Plant Sci. 2006;11:543-9.

[2] Forestier M, King P, Zhang LP, Posewitz M, Schwarzer S, Happe $\mathrm{T}$, et al. Expression of two [Fe]-hydrogenase in Chlamydomonas reinhardtii under anaerobic conditions. Eur. J. Biochem. 2003;270:2750-8.

[3] Gilligan PH, Lum G, Vandamme PAR, Whittier S. Burkholderia, Stenotrophomonas, Ralstonia, Breuundimonas, Comamonas, Delftia, Pandoraea, and Acidivorax. In: Murray PR, editor. Manual of clinical microbiology. Washington DC: ASM Press; 2003. p. 729-48.

[4] Grimault V, Prior P. Invasiveness of Pseudomonas solanacearum in tomato, eggplant and pepper: a comparative study. Eur. J. Plant Pathol. 1994;100:259-67.

[5] Happe T, Mosler B, Naber JD. Induction, localization and metal content of hydrogenase in the green alga Chlamydomonas reinhardtii. Eur. J. Biochem. 1994;222:769-74.

[6] Harris EH. The Chlamydomonas sourcebook. In Introduction to Chlamydomonas and its laboratory use. 2nd edn. City, San Diego: Academic Press, Inc.; 2009.

[7] Jiang Y, Yang Y, Chen HH, Li WJ, Xu LH. The endophytic bacteria resources of botany. Acta Microbiol. Sin. 2005;32:146-7.

[8] Kawaguchi $\mathrm{H}$, Hashimoto K, Hirata $\mathrm{K}$, Miyamoto $\mathrm{K}$. $\mathrm{H}_{2}$ production from algal biomass by a mixed culture of Rhodobium marinum A-501 and Lactobacillus amylovorus. J. Biosci. Bioeng. 2001;91:277-82.

[9] Kim MS, Baek JS, Yun YS, Sim SJ, Park S, Kim SC. Hydrogen production from Chlamydomonas reinhardtii biomass using a two-step conversion process: anaerobic conversion and photosynthetic fermentation. Int. J. Hydrogen Energy 2006;31:812-6.

[10] Laffineur K. Bacteremia due to a novel Microbacterium species in a patient with leukemia and description of Microbacteriumparaoxydans sp. In: Avesani V, Cornu G, Charlier J, Janssens M, Wauters G, Delmée M, editors. J. Clin Microbiol. 2003:2242-6.
[11] Makarova VV, Kosourov S, Krendeleva TE, Semin BK, Kukarskikh GP, Rubin AB, et al. Photoproduction of hydrogen by sulfur-deprived Chlamydomonas reinhardtii mutants with impaired photosystem II photochemical activity. Photosynth. Res. 2007;94:79-89.

[12] Melis A, Melnicki MR. Integrated biological hydrogen production. Int. J. Hydrogen Energy 2006;31:1563-73.

[13] Melis A, Zhang L, Forestier M, Ghirardi ML, Seibert M. Sustained photobiological hydrogen gas production upon reversible inactivation of oxygen evolution in the green alga Chlamydomonas reinhardtii. Plant Physiol. 2000;122:127-36.

[14] Melis A. Photosynthetic $\mathrm{H}_{2}$ metabolism in Chlamydomonas reinahrdtii. Planta 2007;226:1075-86.

[15] Miura Y, Saitoh C, Matsuoka S, Miyamoto K. Stably sustained hydrogen production with high molar yield through a combination of a marine green alga and a photosynthetic bacterium. Biosci. Biotechnol. Biochem. 1992;56:751-4.

[16] Ohmiya K, Sakka K, Kimura T, Morimoto K. Application of microbial genes to recalcitrant biomass utilization and environmental conservation. J. Biosci. Bioeng 2003;95:549-61.

[17] Nelson KE, Weinel c, Fraser CM. Complete genome sequence and comparative analysis of the metabolically versatile Pseudomonas putida KT2440. Environ. Microbiol. 2002;4:799-808.

[18] Park Y, Je KW, Lee K, Sang EJ, Choi TJ. Growth promotion of Chlorella ellipsoidea by co-inoculation with Brevundimonas sp. isolated from the microalga. Hydrobiologia 2008;598:219-28.

[19] Regensburger B, Meyer L, Fuser M, Weber J, Studer D, Lamb JW, et al. Bradyrhizobium japonicum mutants defective in root-nodule bacteroid development and nitrogen fixation. Arch. Microbiol. 1986;144:355-66.

[20] Rivas MO, Vargasand P, Riquelme CE. Interactions of Botryococcus braunii cultures with bacterial biofilms. Microbiol Ecol 2010;60:628-35.

[21] Sambrook J, Fritsch EF, Maniatis T. Molecular cloning: a laboratory manual. New York: Cold Spring Harbor Laboratory Press; 2001.

[22] Shi LM, Cai YF, Li PF. Molecular identification of the colonyassociated cultivable bacteria of the cyanobacterium Microcystis aeruginosa and their effects on algal growth. J. Freshw. Ecol. 2012;24:211-8.

[23] Watanabe KN, Takihana N, Aoyagi H. Symbiotic association in Chlorella culture. FEMS Microbiol. Ecol. 2005;51:187-96.

[24] Wu SX, Li XX, Yu J, Wang QX. Increased hydrogen production in co-culture of Chlamydomonas reinhardtii and Bradyrhizobium japonicum. Bioresour. Technol. 2012;123:184-8.

[25] Wu SX, Yan GY, Xu LL, Wang QX, Liu XL. Improvement of hydrogen production with expression of lba gene from soybean in chloroplast of Chlamydomonas reinhardtii. Int. J. Hydrogen Energy 2010;35:13419-26.

[26] Xu L, Yan G, Wang Q Wu S. Optimization of culture conditions of hydrogen production of Chlamydomonas reinhardtii and its transgenic strain. China Biotechnol. 2010;30:44-9. 